\title{
Predicate catenae A dependency grammar analysis of it-clefts
}

\author{
Timothy Osborne \\ Zhejiang University \\ Hangzhou, China \\ tjo3ya@yahoo.com
}

\begin{abstract}
This manuscript proposes a syntactic analysis of $i t$-cleft sentences in English in dependency syntax. The connectivity effects of $i t$-clefts are addressed in terms of the catena unit. A central claim is that despite the presence of two finite clauses, the matrix predicate of $i t$-clefts, which is a catena, reaches into the embedded clause to include the primary predicate residing there. This means that despite the presence of two finite verbs, $i t$-clefts are in fact mono-clausal in a central way. Given this essentially mono-clausal status of $i t$-clefts, the widely discussed connectivity effects that appear in them are not surprising.
\end{abstract}

\section{Introduction}

The connectivity effects of $i t$-clefts, pseudoclefts, and specificational copular sentences in general challenge theories of syntax in a central way and have therefore helped give rise to an unending stream of studies into these sentence types over the past few decades (e.g. Akmajian 1970; Gundel 1977; Delahunty 1984, 1986; Heggie 1988; Moro 1997; Heycock \& Kroch 1999, Hedberg 2000; Mikkelsen 2004; Reeve 2012; among many others). This contribution demonstrates that a dependency grammar (DG) that acknowledges the $c a$ tena unit (O'Grady 1998; Osborne 2005; Osborne et al. 2012) is in a particularly strong position to account for the connectivity effects of these sentence types. The focus here, however, is on only one of these three sentence types, namely it-clefts.

The core phenomenon examined in this manuscript is illustrated with sentence (1):

(1) It was herself $\mathbf{1}_{\mathbf{1}}$ that $\mathbf{J i l l}_{\mathbf{1}}$ critiqued.

The reading indicated by co-indexation is natural in this case. This is a surprising state of affairs in view of the fact that herself appears in the matrix clause, the clause associated with the finite copula was, whereas the full noun with which it is co-indexed appears in the embedded clause associated with the finite content verb critiqued. Compare sentence (1) with sentence (2) in this regard:

(2) *They told herself $\boldsymbol{1}_{\mathbf{1}}$ that $\mathbf{J} \mathrm{Ill}_{\mathbf{1}}$ was too critical.

Despite the outward similarity of sentence (2) to sentence (1), sentence (2) is clearly bad. The reflexive pronoun herself in the matrix clause cannot take its reference from the full noun Jill in the embedded clause. The acceptability contrast across (1) and (2) reveals that it-cleft sentences behave uniquely regarding binding patterns. The greater phenomenon is known as connectivity. The foregrounded constituent in cleft sentences behaves as though it is "connected" into a simple clause, in the case of (1) the simple clause being Jill critiqued herself.

This manuscript demonstrates that a flexible understanding of predicates and their arguments can capture this behavior of $i t$-clefts. The central claim is that the matrix predicate in $i t$-clefts reaches into the embedded clause to include the main predicate there. The following dependency tree of sentence (1) presents the account in brief: 
(3)

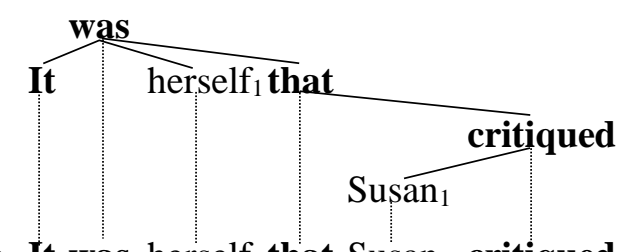

a. It was herself that $\operatorname{Susan}_{1}$ critiqued.

b. IT WAS THAT CRITIQUED (SUSAN 1, HERSELF $_{1}$ )

The words in bold in (3a) form a catena and this catena is the matrix predicate of the entire sentence. The arguments of this predicate are Susan and herself. The predicate-argument analysis of (3a) is given in (3b) according to the convention of predicate-calculus (and using small caps): the predicate is placed on the left and its arguments are listed in parenthesis to the right of the predicate. The key insight concerning this analysis is that the matrix predicate is a catena that includes the expletive $i t$, the two finite verbs was and critiqued as well as the subordinator that.

By acknowledging that the matrix predicate is a catena in this manner, it becomes possible to account for connectivity effects in representational terms in surface syntax. Appeals to transformations/derivations that derive it-cleft sentences from more basic sentence types (e.g. Akmajian 1970; Pinkham \& Hankamer 1975; Emonds 1976; Meinunger 1998; Reeve 2012) and/or appeals to semantic or logical structures (Heycock \& Kroch 1999; Lahousse 2009), e.g. Logical Form, are not necessary. Connectivity effects also appear in pseudocleft and specificational copular sentences in general. While the theoretical apparatus developed here can be extended to these related sentence types, no attempt to do so is undertaken here due to length limitations. The manuscript is organized as follows. Section 2 illustrates and discusses connectivity effects in it-clefts more extensively. Section 3 provides some background discussion concerning varying notions of predicates. Section 4 establishes that matrix predicates are catenae. Section 5 presents the core analysis of connectivity effects in $i t$-clefts in terms of the catena unit. Section 6 draws attention to two additional aspects of $i t$-clefts. Section 7 concludes the manuscript.

\section{Connectivity effects}

The next examples illustrate the effect of Condition A of the traditional binding theory (Chomsky 1981, 1986). Condition $\mathrm{A}$ is the requirement in GB (Government and Binding) binding theory that requires a reflexive pronoun to have a local antecedent, roughly a clause-mate, e.g.

\section{Condition A violated}

(4) a. *They told himself $\mathbf{1}_{1}$ that Tom $_{1}$ was injured.

b. *It surprised herself ${ }_{1}$ that Susan $_{1}$ won the prize.

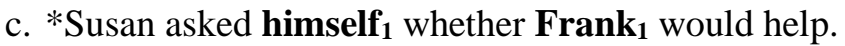

These sentences are robustly ungrammatical because Condition A is violated each time: the reflexive pronoun is not locally c-commanded by an antecedent; that is, Tom, Susan, and Frank do not locally c-command himself, herself, and himself, respectively. Note that each of these sentences contains two finite clauses, each headed by a finite verb.

It-cleft sentences can have an outward appearance that is similar to sentences (4a-c), yet the presence of the reflexive pronoun is perfectly acceptable (cf. Delahunty 1984: 69; Lahouse 2009; Reeve 2012: 42):

Condition A obviated

(5) a. It was himself 1 that Tom 1 injured.

b. It was herself $\mathbf{f}_{1}$ that Susan $_{1}$ surprised.

c. It was himself $\boldsymbol{1}_{\mathbf{1}}$ that Frank $_{\mathbf{1}}$ asked to help.

The perfect grammaticality of these sentences is unexpected based on the ungrammaticality of sentences (4a-c). Each sentence in both sets is bi-clausal, whereby both clauses are headed by a finite verb. Furthermore, the embedded clauses across the two sets are similar in that they are all introduced by the subordinator 
that. Apparently, some trait of it-clefts fundamentally alters the basic binding relationships such that Condition A is obviated.

The situation is the same concerning the other two conditions of the traditional binding theory, that is, it-clefts also appear to ignore Conditions B and C. Condition B of the GB binding theory states that a nonreflexive pronoun must be free in its local binding domain, and Condition $\mathrm{C}$ of GB binding theory states a fully referential expression, an R-expression, must be free everywhere. To illustrate, each data set now contains three sentences, whereby the a-sentence illustrates the normal situation associated with the binding condition at hand and the b-sentence shows that the cleft sentence ignores this condition. The c-sentences are added to establish a point about mono-clausality:

\section{Condition B}

(6) a. They told him $\mathbf{h}_{1}$ that he $\mathbf{h}_{1}$ was injured.

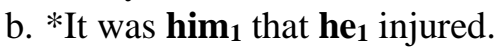

c. $*{ }^{*} \mathbf{H e}_{\mathbf{1}}$ injured $\mathbf{h i m}_{1}$.

Condition $\mathrm{C}$

(7) a. They told Tom $_{1}$ that he 1 was injured.

b. *It was $\mathbf{T o m}_{1}$ that he $\mathbf{h}_{1}$ injured.

c. $* H_{1}$ injured Tom $_{1}$.

Based on the perfect acceptability of the readings in (6a) and (7a), the readings indicated in the it-clefts in (6b) and (7b) are unexpectedly unavailable. The c-sentences draw attention to the fact that it-clefts behave like mono-clausal sentences in this area despite the fact that $i t$-clefts are bi-clausal, containing two finite verbs.

Examples (6-7) suggest an approach to it-clefts that derives them from the corresponding non-cleft counterparts - (6b) from (6c) and (7b) from (7c). An important insight in this regard is that the order of the coindexed nominals in each cleft sentence above would match that of the corresponding non-cleft counterpart in which topicalization has occurred:

(8) a. It was himself 1 that Tom $_{1}$ injured. $=(5 a)$

b. ...but himself $\mathbf{T}_{\mathbf{1}}$ Tom $_{1}$ did injure.

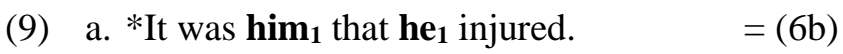

b. *...but him he $_{1}$ did injure.

(10) a. *It was Tom That $_{1}$ injured. $\quad=(7 \mathrm{~b})$

b. *...but Tom $\mathbf{1}$ he $\mathbf{1}_{1}$ did injure.

The bolded nominals across each pair match with respect to linear order of appearance and the syntactic function that each fulfills; himself each time, him each time, and Tom each time are all objects of injured/injure.

The insight is supported by most so-called anti-connectivity effects (cf. Pinkham \& Hankamer 1975: 431; Delahunty 1986: 34; Lahousse 2009: 143-145; Reeve 2012: 44). The binding behavior of it-clefts does not necessarily match that of the corresponding non-cleft counterpart as illustrated with the following bsentences. It does, however, match that of the corresponding non-cleft counterpart in which topicalization has occurred as illustrated with the c-sentences:

(11) a. It was himself $\mathbf{f}_{1} /$ him $_{\mathbf{1}}$ that Bill 1 asked Sue to wash. (Pinkham \& Hankamer 1975: 431)

b. Bill ${ }_{1}$ asked Sue to wash $*$ himself $/$ him $_{1}$.

c. ...but himself $1 / * \mathbf{h i m}_{1}$ Bill $_{1}$ did ask Sue to wash.

(12) a. It was herself $1 / *^{*}$ her $_{1}$ that Sue $_{1}$ said Bill wants to date.

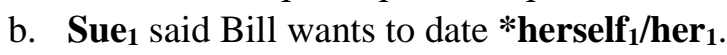

c. ...but herself $1 /{ }^{*}$ her $_{1}$ Sue $_{1}$ did say Bill wants to date.

The distribution of pronoun forms in the cleft sentences does not match that of the corresponding non-cleft counterpart in which standard SVO word order obtains (b-sentences). It does, however, match that of the sentences in which OSV order obtains due to topicalization (c-sentences). 
To summarize so far, the binding pattern of $i t$-cleft sentences can match that of their corresponding noncleft counterparts in which topicalization has occurred, whereby the foregrounded constituent of the cleft sentence corresponds to the topicalized constituent in the non-cleft counterpart. When the non-cleft counterpart is mono-clausal, the corresponding cleft sentence also behaves as if it is mono-clausal despite the presence of two finite verbs. When the non-cleft sentence is bi-clausal, the foregrounded constituent of the corresponding cleft sentence behaves like a topicalized constituent in the non-cleft counterpart.

The insight established with the examples so far extends to other phenomena, such as to the ambiguities associated with negation and a causal adjunct (13a-c), the distribution of the negative polarity item any (14ac), and ambiguities of quantifier scope (15a-c):

Negation and causal adjunct

(13) a. Frank did not leave because he had to work.

b. It was because he had to work that Frank did

(not $>$ because, not $<$ because) not leave.

c. Because he had to work, Frank did not leave. (because $>$ not, *because $<$ not)

Distribution of NPI any

(14) a. Frank did not insult anyone.

b. *It was anyone that Frank did not insult.

c. *...but anyone Frank did not insult.

Ambiguities of quantifier scope
a. Every boy kissed a girl.
$(a>$ every, every $>$ a)
b. It was a girl that every boy kissed.
(a $>$ every, every $>$ a)
(cf. Reeve 2012: 42)
c. ...but a girl every boy did kiss. $\quad(a>$ every, every $>$ a)

The ambiguity of (13a) disappears in the corresponding cleft sentence that foregrounds the causal adjunct (13b), just as it disappears in the corresponding simple sentence that has experienced topicalization of the adjunct (13c). ${ }^{1}$ The polarity item any- follows its trigger not in (14a), but when it precedes it in the corresponding cleft sentence, the sentence is ungrammatical, just as the corresponding simple sentence (14c) is ungrammatical in which the object anyone has been topicalized. Concerning examples (15a-c), all three sentences are ambiguous in the same way. The relevant point in this regard is that just as the ambiguity of (15a) is maintained in the cleft sentence (15b), so too it is maintained in the corresponding simple sentence with topicalization (15c).

The examples discussed so far all have the object as the foregrounded constituent in the it-cleft. When the subject is foregrounded instead of an object, the $i t$-cleft also patterns like the corresponding simple sentence:

\section{Binding (Condition A)}

a. It was Sam $\mathbf{1}_{1}$ who hurt himself 1 .

b. Sam 1 hurt himself 1 .

Negation and causal adjunct

a It was Frank who did not leave because he had to work. (not $>$ because, not $<$ because)

b. Frank did not leave because he had to work. $\quad$ (not $>$ because, not $<$ because)

Distribution of NPI any

(18) a. It was Frank who did not insult anyone.

b. Frank did not insult anyone.

\footnotetext{
${ }^{1}$ The use of terminology here suggests a transformational approach to syntax, e.g. "foregrounds" and "topicalization". This terminology should be understood in a metaphorical sense and is used in the interest of vivid descriptions that are accessible to a wide audience. The DG espoused here is strictly monostratal in syntax, which means all transformations are rejected that would derive some sentences from other, more basic sentences.
} 
(19) a. It was every boy that kissed a girl.

a. It was every boy that kissed a girl. $\quad$ (every $>$ a; every $<$ a)

b. Every boy kissed a girl. $\quad$ (every $>$ a; every $<$ a)

In these cases, foregrounded constituent in the it-cleft sentence is the subject. Each time the $i t$-cleft sentence, the a-sentence, patterns just like the corresponding simple sentence, the b-sentence. Topicalization in the simple sentence is not needed because the linear order of the bolded constituents is already consistent across the two sentence types.

To summarize the data, it-cleft sentences pattern just like the corresponding simple sentences with respect to a number of phenomena of syntax. To ensure completeness of the correspondence, however, one must control for linear order. Doing so necessitates that topicalization occur in the simple sentence if the foregrounded constituent in the corresponding it-cleft is a non-subject. This state of affairs suggests strongly that it-clefts are in fact mono-clausal in a central respect, despite the appearance of two finite verbs.

\section{Predicates}

There are two main competing views of what qualifies as a main clause predicate in theories of grammar, a fact that can be verified by a quick check in most dictionaries of linguistic terminology (e.g. Routledge Dictionary of Grammatical Terms in Linguistics 1993, p. 213; Oxford Concise Dictionary of Linguistics 1997, p. 291), and within one of these views, two distinct sub-views can be discerned. The following diagram gives an overview:

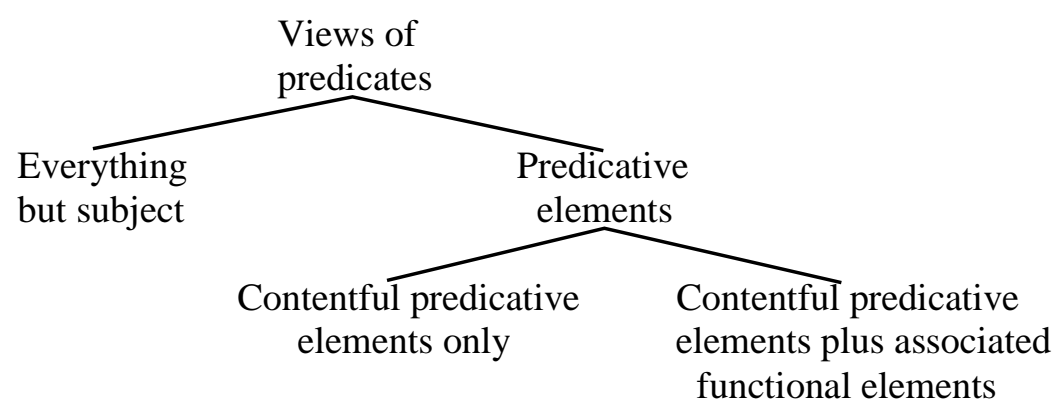

The following sentence is used to illustrate these views of predicates:

(21) Frank has been studying syntax.

The one prominent understanding of predicates takes everything in a simple sentence except the subject as the predicate of the sentence. Hence on this approach, the predicate in (21) is has been studying syntax. This understanding of predicates is compatible with traditional phrase structure syntax insofar as the predicate corresponds to the VP of the initial binary division of a sentence $\mathrm{S}$ into a subject NP and a predicate VP (S $\rightarrow \mathrm{NP}$ VP).

The main alternative understanding of predicates is inspired by predicate calculus associated above all with Gottlob Frege (1848-1925). A predicate serves to assign a property to an argument or to relate more than one argument to each other. On this approach, the content verb studying is deemed as (the core of) the main predicate in sentence (21), and Frank and syntax are its arguments. Within this alternative approach to predicates, one can discern two sub-views. The one sub-view takes predicates and their arguments as semantic entities that are often manifest as content verbs or adjectives (e.g. Poole 2002: 77-79; Adger 2003: 78-82; Carnie 2013: 57-60); on this sub-view, the matrix predicate in (21) is the content verb studying alone. The other sub-view is oriented more toward surface syntax; it takes predicates to consist of at least one main content word plus one or more associated function words. On this sub-view, the matrix predicate in (21) is has been studying.

These competing views of predicates are summarized as follows. The matrix predicate on each view appears in bold: 
Everything but subject:

(22) a. Frank has been studying syntax.

Content predicative word only:

b. Frank has been studying syntax.

Content predicative word plus associated function words:

c. Frank has been studying syntax.

The view of predicates given as (22c) is the one pursued here below. A predicate consists of one or more content words plus any associated function words. Variants of this approach to predicates have been developed in detail (see e.g. Napoli 1989 and Ackermann and Webelhuth 1998). It is also the understanding of predicates that is dominant in the grammars of German (e.g. Helbig and Buscha 1998: 536-543; Duden 1984: 567-571). Most importantly, it represents an approach to predicate-argument structures that is particularly congruent with dependency syntax. This congruity is due to the fact that the word combinations that qualify as predicates are catenae in surface syntax, and so are the arguments of these predicates.

\section{Predicate catenae}

The main insight about predicates and arguments that makes the current account of $i t$-clefts possible is that these entities are manifest as catenae in dependency structures. This fact is established and illustrated here using a series of examples, whereby traditional predicate-calculus-style analyses, as first appeared in (3b) above, are included to make the illustrations more concrete.

A catena is a word or a combination of words that are linked together by dependencies (O'Grady 1999; Osborne 2005; Osborne et al. 2012). ${ }^{2}$ A typical matrix predicate consists of a content verb and any pure auxiliaries that are present. This fact is illustrated first using the example from above about Frank studying syntax:

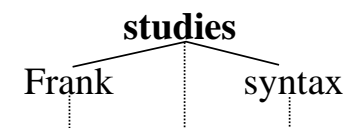

a. Frank studies syntax.

b. STUDIES (FRANK, SYNTAX)
(24)

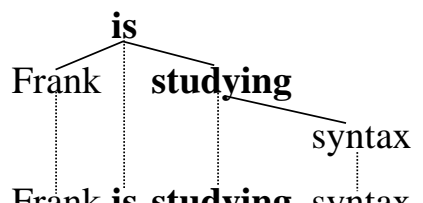

a. Frank is studying syntax.

b. IS STUDYING (FRANK, SYNTAX)

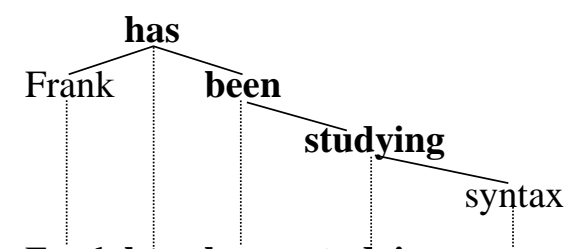

a. Frank has been studying syntax.

(26)

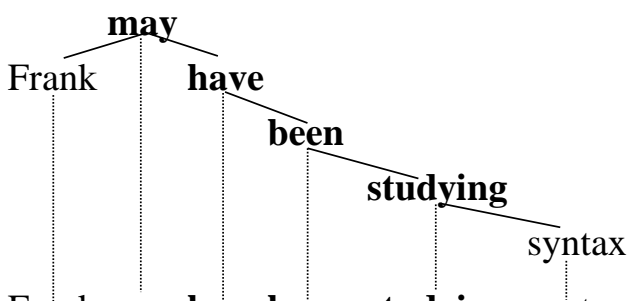

a. Frank may havebeen studying syntax.

b. HAS BEEN STUDYING (FRANK, SYNTAX)

Each additional auxiliary verb that appears is easily incorporated into the matrix predicate. On occasion, the words that constitute the matrix predicate are not linearly continuous, a fact illustrated here using two examples from German:

\footnotetext{
${ }^{2}$ A more formal definition of the catena unit, a set-theoretic one, is given next:

Catena (set-theoretic definition)

Given a dependency tree $\mathrm{T}$, a catena is a set of nodes $\mathrm{N}$ in $\mathrm{T}$ such that exactly one node in $\mathrm{N}$ is not immediately

dominated by another node in $\mathrm{N}$.
} 
(27)

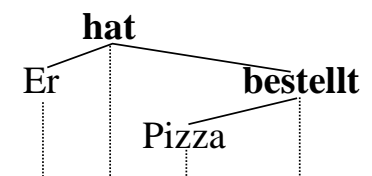

a. Er hat Pizza bestellt.

he has pizza ordered

'He ordered pizza.'

b. HAT BESTELLT (ER, PIZZA)
(28)

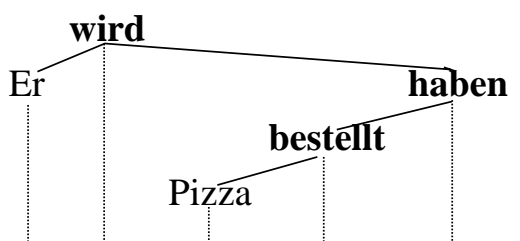

a. Er wird Pizza bestellt haben.

he will pizza ordered have

'He will have ordered pizza.'

b. WIRD BESTELLT HABEN (ER, PIZZA)

Due to the appearance of Pizza in these cases, the words that constitute the matrix predicate are not linearly continuous. This fact does not prevent them from forming a catena.

The next examples concern the auxiliary verb $b e$. This verb is usually semantically almost empty and hence a pure function word. It forms a predicate with (one of) its post-dependent(s). The next examples involve a predicative adjective and a predicative nominal:

(29)

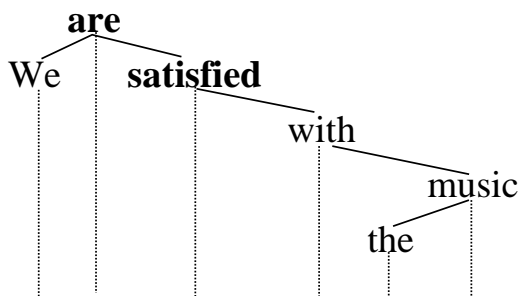

a. We are satisfied with the music.

b. ARE SATISFIED (WE, WITH THE MUSIC)
(30)

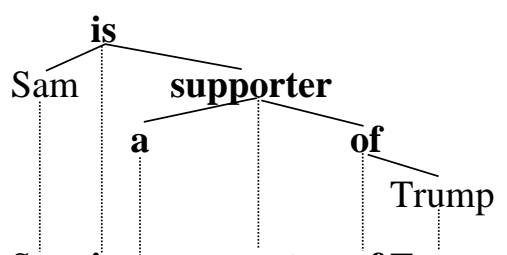

a. Sam is a supporter of Trump.

b. IS A SUPPORTER OF (SAM, TRUMP)

The copula are in (29) forms the matrix predicate with the predicative adjective satisfied, and the copula is in (30) forms the matrix predicate with predicative nominal a supporter of. Note that there is flexibility concerning the status of the prepositions with and of in these two examples, that is, concerning their inclusion or exclusion from the matrix predicate. Alternative analyses in this regard might also be plausible: ARE SATISFIED WITH (WE, THE MUSIC) and IS A SUPPORTER (SAM, OF TRUMP). On either analysis each time, the matrix predicate is a catena. Note also that the matrix predicate is a supporter of in (30) corresponds to a simple content verb supports in the almost synonymous simple sentence Sam supports Trump: SUPPORTS (SAM, TRUMP).

The next examples further illustrate the extent to which forms of auxiliary be appear in the matrix predicate with whatever occurs as their post-dependent. Prepositions can be directly included in the matrix predicate, whereby the object of the preposition is an argument:

(31)

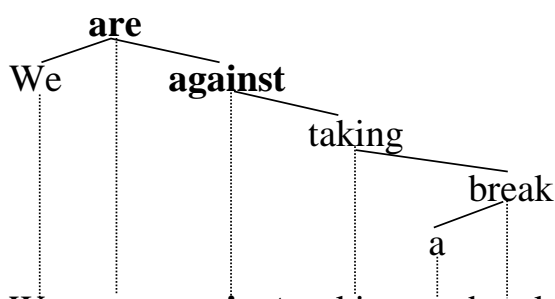

a. We are against taking a break.

b. ARE AGAINST (WE, TAKING A BREAK)
(32)

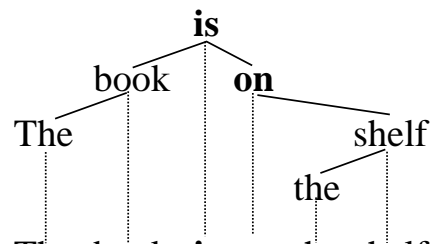

a. The book is on the shelf.

b. IS ON (THE BOOK, THE SHELF)

Examples (29-32) are particularly relevant to the analysis of clefts. They show the manner in which the matrix predicate includes the copula and (part of) a post-dependent of the copula. For cleft sentences, this means that the matrix predicate reaches into the embedded clause. 


\section{Connectivity accounted for}

Many matrix predicates do not reach below the main content verb. This is certainly the case in example (2) above, which is reproduced here as example (33), with the dependency structure and predicate-argument analysis added:

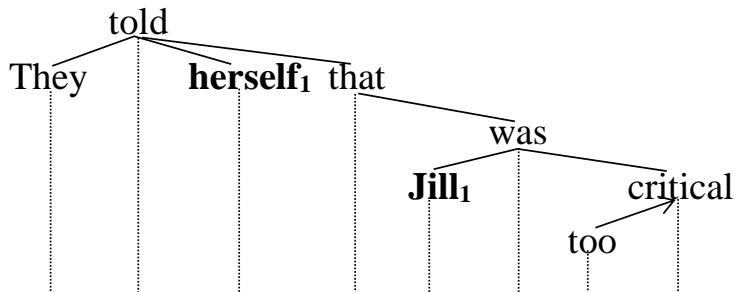

a. *They told herself $\mathbf{1}_{\mathbf{1}}$ that Jill $_{\mathbf{1}}$ was too critical.

b. TOLD (THEY, HERSELF 1 , THAT JILL 1 WAS TOO CRITICAL).

The source of the ungrammaticality in this case is apparent based on the predicate-argument analysis. The reflexive pronoun herself fails to find an antecedent at its level of the predicate-argument structure; Jill is not its co-argument, but rather is embedded in its co-argument.

The next examples demonstrate that when the reflexive pronoun is licensed, its antecedent is often a coargument that is ranked higher on the scale of argument functions: SUBJECT $>1^{\text {ST }}$ OBJECT $>2^{\text {ND }}$ OBJECT $>$ OBLIQUE OBJECT.

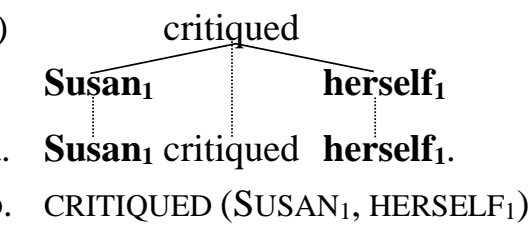

The reflexive pronoun herself is the object of critiqued, and its antecedent is Susan, the subject of critiqued. Thus, herself can appear by virtue of the fact that it finds a more highly ranked co-argument as its antecedent.

The predicate-argument analysis of $i t$-clefts is similar. The matrix predicate reaches down from the root copula to include the main predicate in the embedded clause, rendering the foregrounded constituent a coargument of the argument(s) in the embedded clause. Example (3) is repeated here as (35):

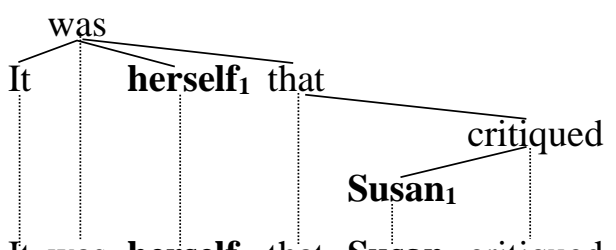

a. It was herself $\mathbf{1}_{1}$ that Susan $_{1}$ critiqued.

b. IT WAS THAT CRITIQUED (SUSAN 1, HERSELF $_{1}$ )

Despite the fact that herself $f_{l}$ appears in the matrix clause, it can take its reference from the argument in the embedded clause. It can do this because the matrix predicate reaches into the embedded clause in a manner that renders Susan and herself co-arguments, whereby Susan, as a subject, is ranked higher than herself, an object. Two key aspects of this analysis are worth restating: first, the copula is a function word and so the matrix predicate necessarily reaches below it to include (part of) a post-dependent, just as in examples (2932) above; and second, the words constituting the matrix predicate form a catena despite the fact they are discontinuous in the linear dimension and hence do not form a string.

A third aspect of example (35) is tentative: the expletive It is included as part of the matrix predicate. Nothing crucial rides on this aspect of the account. An alternative analysis would exclude the expletive $I t$ from the matrix predicate. The advantage of including it therein is that one is not confronted with the challenge of having to decide how to categorize it: should the expletive be viewed as an argument, an adjunct, or something else? 
The next example illustrates the ability of the matrix predicate catena of an it-cleft to be very long indeed. The sentence is from Delahunty (1986: 22), whereby the dependency structure and predicate-argument analysis have been added:

(36)

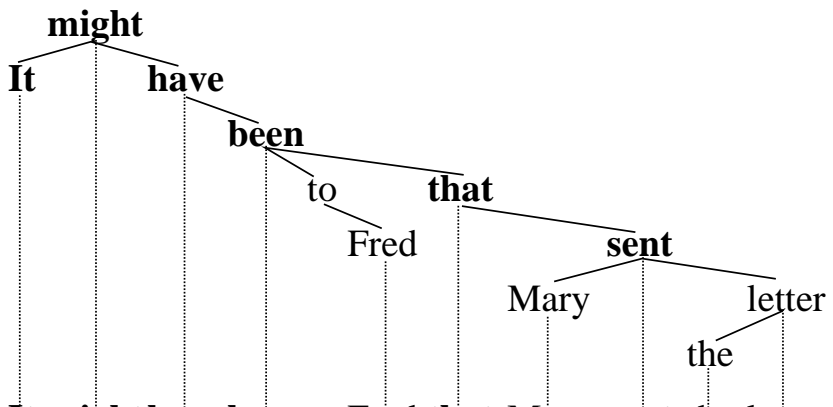

a. It might havebeen to Fred that Mary sent the letter.

b. IT MIGHT HAVE BEEN THAT SENT (MARY, THE LETTER, TO FRED)

The matrix predicate includes six words, only one of which can be viewed as a full content word, namely sent, which is the lowest of the six. We see again that a typical aspect of matrix predicates is the manner in which they reach down from the root of the sentence until they include a full content word.

Example (35) demonstrates how the connectivity associated with binding Condition A is addressed and accommodated in terms of predicate catenae. The same reasoning applies to the other connectivity effects discussed and illustrated in Section 2. These connectivity effects are expected by virtue of the fact that the matrix predicate in an it-cleft sentence reaches down to include the main predicate in the embedded clause.

\section{Two further aspects}

Before concluding this manuscript, two further aspects of the current account are briefly addressed. The first of these concerns the fact that the matrix predicate of $i$-clefts reaches into the embedded clause, but not into the foregrounded constituent. The second concerns the ability of the matrix predicate to include the relative pronoun of the embedded clause.

A widely acknowledged fact about $i t$-clefts is that a verb phrase may not be foregrounded, e.g.

(37) a. *It is blow up some buildings that you should. (Emonds 1976: 133)

b. *It's submit her manuscript to Fortune that Alice did. (cf. McCawley 1998: 66)

c. *It is (to) apply for special leave that you must do. (Huddleston and Pullum 2002: 1422)

A related observation is that other predicative elements, such as predicative adjectives and nominals, also cannot be foregrounded: ${ }^{3}$

(38) a. *It is tall that John is.

b. *It's my doctor that John Smith is.

(Akmajian 1970: 166)

c. *It is on the couch that Frank is.

(Heggie 1988: 81)

The ungrammaticality of examples (37-38) is congruent with the current analysis of it-clefts. The key trait of $i$-clefts established above is that the matrix predicate necessarily reaches into the embedded clause to include the main predicate that resides there. If there is no main predicate there because that predicate appears instead as (part of) the foregrounded constituent, then the matrix predicate would have to reach into the foregrounded constituent; apparently, it cannot do this. The foregrounded constituent of an it-cleft sentence should be an argument or adjunct of the matrix predicate; it cannot include part of the matrix predicate.

The other aspect of $i t$-clefts mentioned here concerns the fact that often, the relative pronoun of the embedded cleft clause is included in the matrix predicate, e.g. It was Bill who we saw.

\footnotetext{
${ }^{3}$ There are some important exceptions to this generalization concerning predicative adjectives. For instance, Heggie (1988: 206) and Reeve (2012: 54-56) observe that if contrastive emphasis is present on the adjective, then predicative adjectives can (at least marginally) be foregrounded, e.g. A: Her eyes are green. B: No, its BLUE that her eyes are, not GREEN.
} 
(39)

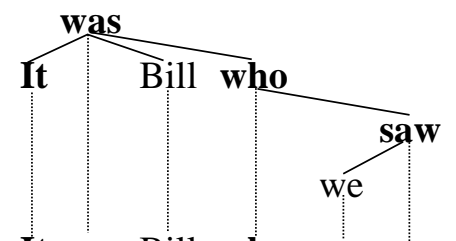

a. It was Bill who we saw.

b. IT WAS WHO SAW (WE, BILL)

This analysis of the embedded cleft clause, which is a type of relative clause, follows the analysis of relative clauses in Groß and Osborne (2009) and Osborne (2014). ${ }^{4}$ The relative pronoun who is positioned as the root of the relative clause. In the current context, the relevant aspect of this analysis is that the relative pronoun can be viewed more as a function word than as a content word, so its inclusion in the matrix predicate is consistent with the account above. Consider in this regard that non-subject relative pronouns are often omitted in English, e.g. the man (who) I know and that when the relative pronoun is a subject followed by a form of be, the two can also be omitted, e.g. the man (who is) studying syntax. These observations help reveal that the relative pronoun is non-essential at times, a fact that increases the plausibility of viewing it as a type of function word.

\section{Concluding statement}

There are of course many aspects of it-clefts that have not been addressed above. Hopefully, however, enough of the current approach to it-clefts has been presented to convince the reader that such an approach is worth pursuing further. Finally, it is appropriate to state again that the current approach in terms of catenae and predicate-argument structures can be extended to related sentence types, namely to pseudoclefts and specificational copular sentences in general. Connectivity effects also appear in these additional sentence types.

\section{References}

Farrell Ackerman and Gert Webelhuth. 1998. A Theory of Predicates. CSLI Publications, Stanford, CA.

David Adger 2003. Core Syntax: A Minimalist Approach. Oxford University Press, Oxford, UK.

Adrian Akmajian.1970. On deriving cleft sentences from pseudo-cleft sentences. Linguistic Inquiry, 1(2):149-168.

Andrew Carnie. 2013. Syntax: A Generative Introduction. Wiley-Blackwell, Malden, MA.

Gerald Delahunty. 1984. The analysis of English cleft sentences. Linguistic Analysis, 13(2):63-113.

Gerald Delahunty. 1986. Topics in the Syntax and Semantics of English Cleft Sentences. Ph.D. thesis, University of California. Reproduced by the Indiana University Linguistics Club.

Duden (Die Grammatik). 1984. Dudenverlag, Mannheim.

Joseph E. Emonds. 1976. A Transformational Approach to English Syntax: Root, Structure-Preserving, and Local Transformations. Academic Press, New York.

Thomas Groß and Timothy Osborne 2009. Toward a practical dependency grammar theory of discontinuities. SKY Journal of Linguistics, 22:43-90.

Jeanette Gundel. 1977. Where do cleft sentences come from? Language, 53(3): 543-559.

Nancy Hedberg. 2000. On the referential status of clefts. Language, 76(4):891-920.

Lorie Heggie. 1988. The Syntax of Copular Structures. Ph.D. dissertation, University of Southern California.

Gerhard Helbig and Joachim Buscha. 1998. Deutsche Grammatik: Ein Handbuch für den Ausländerunterricht, $18^{\text {th }}$ edition. Langenscheidt, Leipzig.

Caroline Heycock and Anthony Kroch. 1999. Pseudo-cleft connectedness: Implications for the LF interface. Linguistic Inquiry, 30(3):365-397.

Caroline Heycock and Anthony Kroch. 2002. Topic, focus, and syntactic representations. Proceedings of WCCFL 21: $101-125$.

Rodney Huddleston and Geoffreey K. Pullum. The Cambridge Grammar of the English Language. Cambridge University Press, Cambridge, UK.

${ }^{4}$ Certain aspects of Groß and Osborne's diagrammatic analysis of relative clauses have been suppressed here because they are not directly relevant to the point at hand. 
Karen Lahouse. 2009. Specificational sentences and the influence of information structure on (anti-)connectivity effects. Journal of Linguistics, 45:139-166.

André Meinunger. 1998. A monoclausal structure for (pseudo) cleft sentences. In: P. N. Tmanji and K. Kusumoto (eds.), Proceedings of NELS, 28:283-297.

Line Mikkelsen. 2005. Copular Clauses: Specification, Predication and Equation. [Linguistik Aktuel1/Linguistics Today 85]. John Benjamins, Amsterdam.

Andrea Moro.1997. The Raising of Predicates. Cambridge University Press, Cambridge, UK.

Donna Jo Napoli. 1989. Predication theory: A case study for indexing theory. Cambridge University Press, Cambridge, UK.

William O'Grady. 1998. The syntax of idioms. Natural Language and Linguistic Theory, 16:279-312.

Timothy Osborne. 2005. Beyond the constituent: A dependency grammar analysis of chains. Folia Linguistica, 39(34):251-297.

Timothy Osborne. 2014. Type 2 rising: A contribution to a DG account of discontinuities. In Kim Gerdes, Eva Hajičova and Leo Wanner (eds.), Dependency Linguistics: Recent Advances in Linguistic Theory using Dependency Structures, 273-298. John Benjamins, Amsterdam.

Timothy Osborne, Michael Putnam and Thomas Groß 2012. Catenae: Introducing a novel unit of syntactic analysis. Syntax, 15(4):354-396.

Oxford Concise Dictionary of Linguistics. 1997. By P.H. Matthews. Oxford University Press, Oxford, UK.

Jessie Pinkham and Jorge Hankamer. 1975. Deep and shallow clefts. In Chicago Linguistics Society Vol. 11, 429-450.

Geoffrey Poole. 2002. Syntactic Theory. PALGRAVE, New York.

Randolph Quirk, Sidney Greenbaum, Geoffrey Leech and Jan Svatvik. 2010. A Comprehensive Grammar of the English Language. Dorling Kindersley (India)/Pearson Education, New Delhi.

Matthew Reeve. 2012. Clefts and their Relatives. John Benjamins, Amsterdam.

Routledge Dictionary of Grammatical Terms in Linguistics. 1993. By R. L. Trask. Routledge, London. 